\title{
Lysosomal $\beta$-glucuronidase regulates Lyme and rheumatoid arthritis severity
}

\author{
Kenneth K.C. Bramwell, ${ }^{1}$ Ying Ma, ${ }^{1}$ John H. Weis, ${ }^{1}$ Xinjian Chen, ${ }^{1}$ \\ James F. Zachary, ${ }^{2}$ Cory Teuscher, ${ }^{3}$ and Janis J. Weis ${ }^{1}$
}

${ }^{1}$ University of Utah, Salt Lake City, Utah, USA. 2University of Illinois, Urbana, Illinois, USA. 3University of Vermont, Burlington, Vermont, USA.

\begin{abstract}
Lyme disease, caused by the spirochete Borrelia burgdorferi, is the most prevalent arthropod-borne illness in the United States and remains a clinical and social challenge. The spectrum of disease severity among infected patients suggests that host genetics contribute to pathogenic outcomes, particularly in patients who develop arthritis. Using a forward genetics approach, we identified the lysosomal enzyme $\beta$-glucuronidase (GUSB), a member of a large family of coregulated lysosomal enzymes, as a key regulator of Lyme-associated arthritis severity. Severely arthritic $\mathrm{C} 3 \mathrm{H}$ mice possessed a naturally occurring hypomorphic allele, Gus $b^{b}$. C57BL/6 mice congenic for the $\mathrm{C} 3 \mathrm{H} \mathrm{Gusb}$ allele were prone to increased Lyme-associated arthritis severity. Radiation chimera experiments revealed that resident joint cells drive arthritis susceptibility. $\mathrm{C} 3 \mathrm{H}$ mice expressing WT Gusb as a transgene were protected from severe Lyme arthritis. Importantly, the Gusb allele also exacerbated disease in a serum transfer model of rheumatoid arthritis. A known GUSB function is the prevention of lysosomal accumulation of glycosaminoglycans (GAGs). Development of Lyme and rheumatoid arthritis in Gus $b^{b}$-expressing mice was associated with heightened accumulation of GAGs in joint tissue. We propose that GUSB modulates arthritis pathogenesis by preventing accumulation of proinflammatory GAGs within inflamed joint tissue, a trait that may be shared by other lysosomal exoglycosidases.
\end{abstract}

\section{Introduction}

Lyme disease, caused by the spirochete Borrelia burgdorferi (1), is the most prevalent arthropod-borne illness in the United States. More than 30,000 cases are reported each year, while estimates suggest that around 300,000 are diagnosed annually $(2,3)$. Disease severity varies greatly among the affected population, with up to $60 \%$ of untreated patients developing a self-limiting, inflammatory arthritis $(4,5)$. Even following appropriate antibiotic therapy, up to $10 \%$ of patients will develop chronic arthritis, which can persist for months to years. While the genetic composition of the spirochete is a critical determinant of the invasive potential of the bacteria (6), other host-associated attributes are also clearly instrumental in determining the severity and duration of symptoms of infection. Polymorphisms in TLR1 and - 2 have been linked to altered innate immune responses to B. burgdorferi, providing strong evidence that host factors contribute to clearance of the pathogen and modulation of innate defenses, both early and late in infection (7-9). However, these polymorphisms do not explain the extent of disease manifestation in infected patients. The strong familial association of other types of arthritis is consistent with the concept that genetic predisposition may trigger a pathological response to inflammatory stimuli, such as bacterial infection. Furthermore, certain of the MHC alleles associated with rheumatoid arthritis have been identified as contributing to antibiotic-refractory Lyme arthritis by some groups, suggesting the possibility of other common mechanisms in immune-mediated stages of disease (10-12).

In a seminal observation, Barthold and colleagues reported that inbred strains of laboratory mice exhibit consistent differences in arthritis severity following infection with B. burgdorferi, and identified the $\mathrm{C} 3 \mathrm{H} / \mathrm{HeJ}$ or $\mathrm{C} 3 \mathrm{H} / \mathrm{HeN}(\mathrm{C} 3 \mathrm{H})$ mouse as display-

Conflict of interest: The authors have declared that no conflict of interest exists. Citation for this article: J Clin Invest. 2014;124(1):311-320. doi:10.1172/JCI72339. ing the most severe disease and C57BL/6 (B6) as displaying less severe disease (13). Key features of arthritis development that are shared between infected $\mathrm{C} 3 \mathrm{H}$ mice and patients with severe Lyme arthritis include synovial hyperplasia, inflammatory cell infiltrate, and exuberant edema. The mouse is one of the major mammalian reservoirs for B. burgdorferi, serving as host for blood meals of the larval and nymphal stages of Ixodes sps vector ticks (14). Studies in the mouse have been critical to our understanding of environmentally regulated changes in gene expression necessary for transition between hosts and the elaborate mechanism of antigenic variation necessary for survival in the immunocompetent host (15).

The imperative health need for understanding the genetic component of human Lyme arthritis prompted us to pursue a forward genetic approach to identify genes responsible for disease severity. Barthold's initial studies (13) identified C3H and $\mathrm{B} 6$ as being at the extreme ends of Lyme disease symptoms, and more recent SNP-based analysis has placed $\mathrm{B} 6$ and $\mathrm{C} 3 \mathrm{H}$ mice on well-separated branches of the mouse family tree (16). B6 is the reference strain for the mouse genome sequence, and $\mathrm{C} 3 \mathrm{H}$ mice were included in the Perlegen Sciences resequencing project, permitting the extensive analysis of variation between these strains. Our work is the outcome of a classic forward genetic approach to identifying regulators of Lyme arthritis severity in mice. Intercross populations between $\mathrm{C} 3 \mathrm{H}$ and $\mathrm{B} 6$ (or BALB/c) mice led to the identification of multiple B. burgdorferi arthritis-associated (Bbaa) quantitative trait loci (QTL) on 5 chromosomes (17). Four individual crosses identified Bbaa2 on mouse chromosome 5, which exhibits the strongest linkage to disease severity, with a maximum lod score of 10.2 (18). Our laboratory previously developed a B6.C $3 \mathrm{H}-B b a a 2 B b a a 3$ congenic mouse line, where Bbaa2Bbaa3 from susceptible $\mathrm{C} 3 \mathrm{H}$ mice was isolated on an otherwise uniform resistant $\mathrm{B} 6$ genetic background $(19,20)$, and found that these mice exhibit increased Lyme arthritis severity, with joint inflammation and histopathology closely resembling the human disease. 


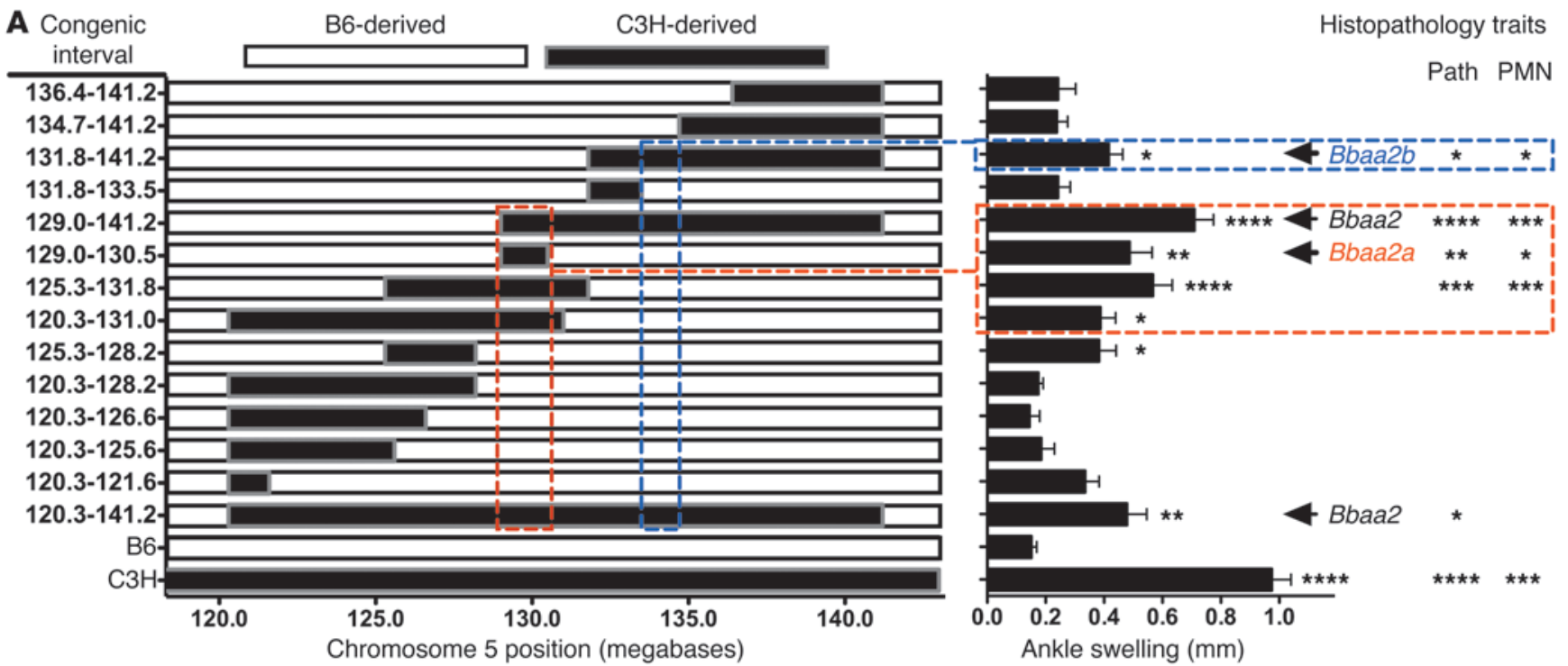

B

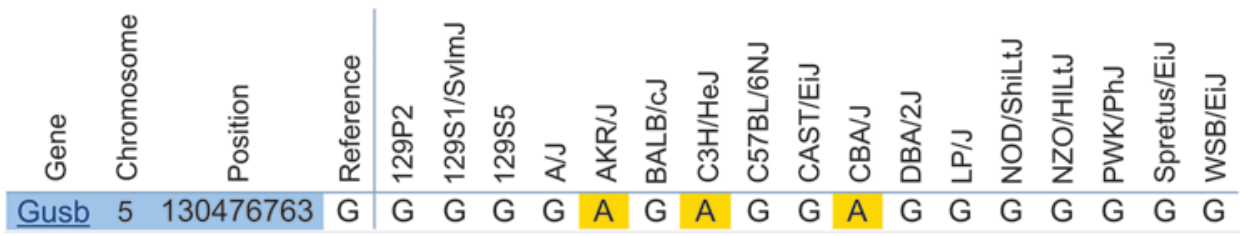

C

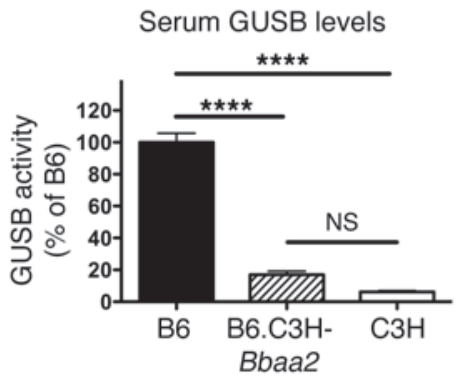

D

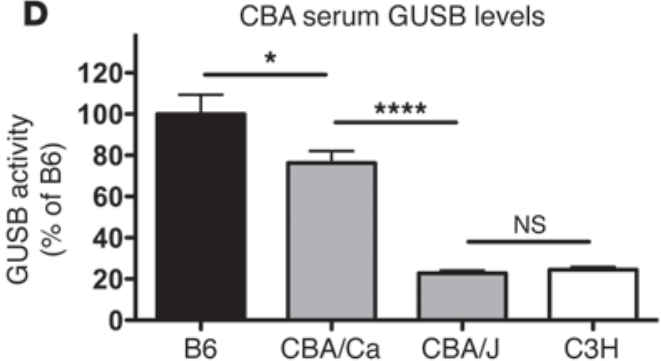

$\mathrm{BMM} \phi$ cell extracts

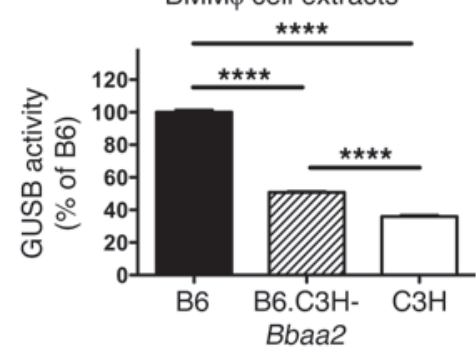

E

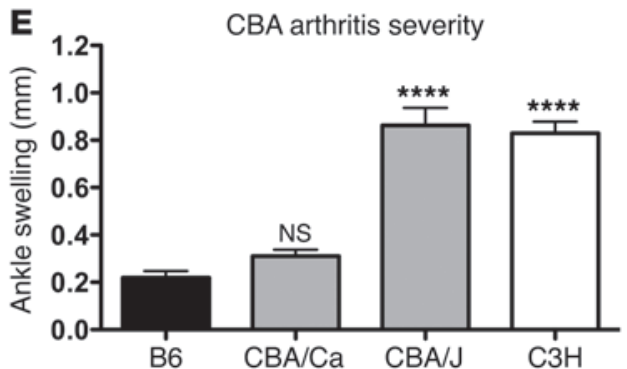

Figure 1

Positional mapping and characterization of the Gusb $b^{h}$ allele. (A) Advanced congenic lines identify regulatory subintervals within $B b a a 2$. Each row represents the genetic makeup of 1 congenic mouse line across the Bbaa2 interval (120.3 to $141.2 \mathrm{Mb}$ ) on mouse chromosome 5 . White and black portions of each row represent areas inherited from the $\mathrm{B} 6$ or $\mathrm{C} 3 \mathrm{H}$ background, respectively. Ankle swelling measurements taken 4 weeks after $B$. burgdorferi infection ( $n=12$ to 35 mice per group; overall $P<0.0001$ ). Significance of cosegregation (right) between ankle swelling and blinded scores of joint histopathology and PMN infiltration, assessed by 1-tailed Mann-Whitney test. (B) Inheritance of the Gusb polymorphism among strains included in the Sanger SNP resequencing database. (C) $\mathrm{C} 3 \mathrm{H}$ mice and congenics carrying the Gusb $b^{h}$ allele exhibited enzymatic hypomorphism in serum and bone marrow-derived macrophage cell extracts and supernatants $(n=4)$. (D) CBA/Ca expressed near normal serum GUSB activity, while CBA/J shared the C3H GUSB hypomorphism. (E) CBA/J developed severe Lyme arthritis, while CBA/Ca were resistant $(n=5$ [B6 and $\mathrm{C} 3 \mathrm{H}]$ and 10 [CBA substrains] mice in each group; overall $P<0.0001)$. Significance assessed by 1 -way ANOVA followed by Dunnet's multiple comparison test versus B6 (A and $\mathbf{E})$ or Bonferroni's post test $(\mathbf{C}$ and $\mathbf{D}) .{ }^{*} P<0.05 ;{ }^{* \star} P<0.01 ;{ }^{* \star \star} P<0.001 ;{ }^{* \star \star \star} P<0.0001$. 
A
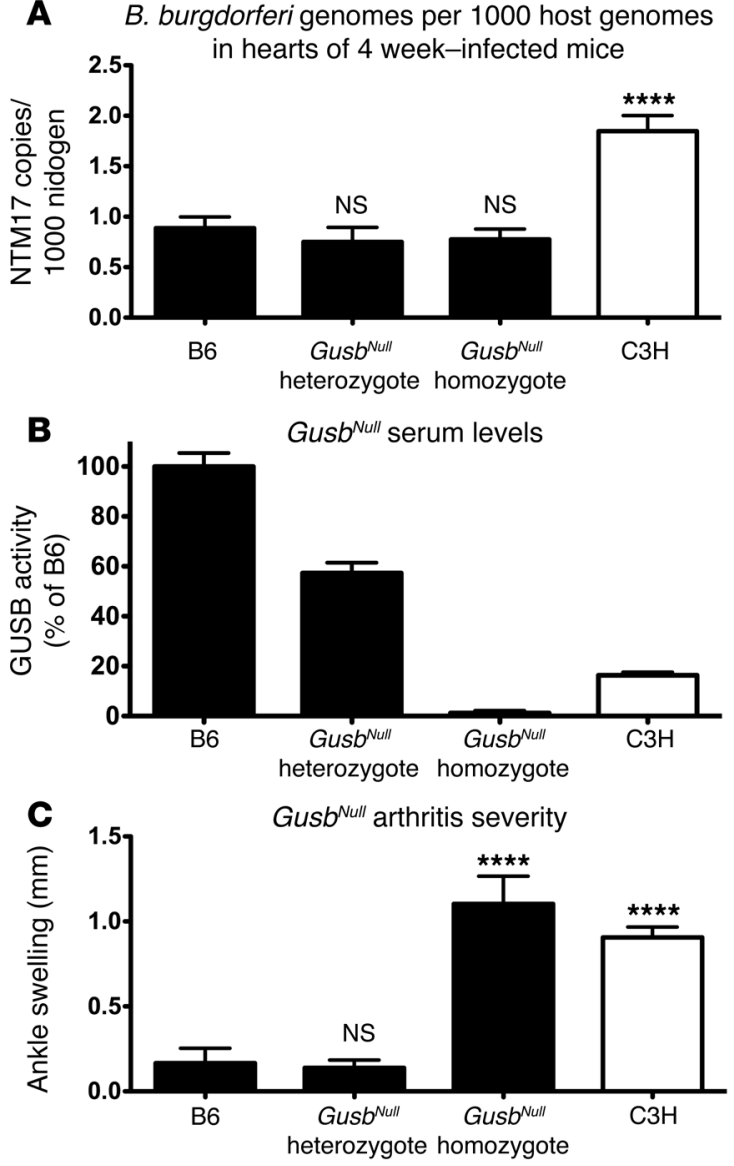
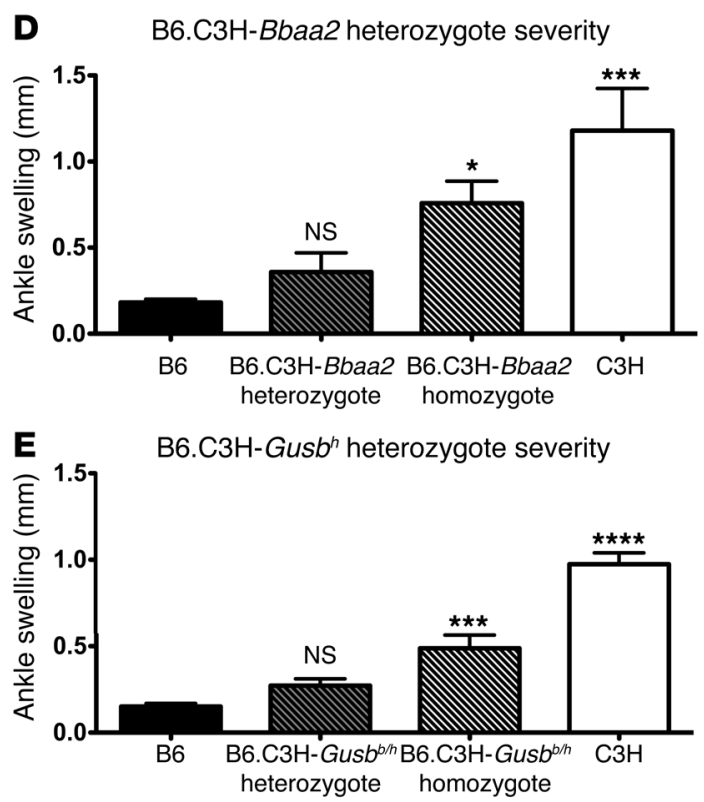

Figure 2

Loss of GUSB function exacerbates Lyme arthritis severity in a genetically recessive manner. (A) Gusb $b^{\text {Null }}$ mice do not exhibit a defect in host defense. The observed difference between $\mathrm{B} 6$ and $\mathrm{C} 3 \mathrm{H}$ genetic backgrounds in heart bacterial burden has been previously described (59). (B) Serum GUSB activity of infected B6 and C3H controls, Gusb $b^{\text {Null }}$ homozygotes, and Gusb $b^{\text {Null }}$ heterozygous littermates ( $n=5$ to 6 per group). (C) Arthritis severity measurements of Gusb ${ }^{\text {Null }}$ homozygotes, heterozygous littermates, and WT B6 and C3H controls ( $n=5$ to 6 per group; overall $P<0.0001$ ). (D and E) Arthritis severity measurements of B6.C3H-Bbaa2 and B6.C3H-Gus $b^{h}$ heterozygotes were statistically indistinguishable from B6 control animals ( $n=5$ per group; overall $P<0.001$ ). Significance assessed by 1 -way ANOVA followed by Bonferroni's multiple comparison test versus B6. ${ }^{\star} P<0.05 ;{ }^{\star \star \star} P<0.001 ;{ }^{* \star \star \star} P<0.0001$.

In this study, we report the positional cloning of a key genetic regulator underlying the increased Lyme arthritis severity conferred by $\mathrm{Bbaa} 2$ in $\mathrm{C} 3 \mathrm{H}$ mice, the lysosomal enzyme $\beta$-glucuronidase, Gusb. The hypomorphic $\mathrm{C} 3 \mathrm{H}$ allele, $\mathrm{Gusb}^{b}$, was found to cause increased arthritis severity in mouse models of both Lyme and rheumatoid arthritis. Gusb belongs to a recently recognized group of lysosomal enzymes that modulate lysosomal storage and function and that are coregulated in response to stress. We propose that mild deficiencies in Gusb and other coregulated lysosomal enzymes may have previously unrecognized impact on a variety of inflammatory pathologies.

\section{Results}

Positional cloning of Gusb. Through additional backcrossing to the parental B6 line, we developed 15 advanced B6.C3H-Bbaa2 congenic mouse lines harboring subintervals of $B b a a 2^{C 3 H}$ from 120.3 to 141.2 Mbp (Figure 1A and ref. 21). After infection with B. burgdorferi, the various subinterval congenic lines exhibited a wide spectrum of disease severity, as assessed quantitatively by ankle swelling measurements. Compared with $\mathrm{B} 6$, congenic mice harboring $\mathrm{C} 3 \mathrm{H}-$ derived intervals from $129.0-130.5 \mathrm{Mbp}(P<0.01), 133.5-141.2 \mathrm{Mbp}$ $(P<0.05)$, and $125.3-128.2 \mathrm{Mbp}(P<0.05)$ within Bbaa2 exhibited significantly more severe disease. The ankle swelling data also support the presence of a negative regulatory element within Bbaa2 (Supplemental Figure 1; supplemental material available online with this article; doi:10.1172/JCI72339DS1). Moreover, for the 129.0-130.5 Mbp and 133.5-141.2 Mbp intervals, increases in the categorical traits of pathology score and neutrophil (PMN) infiltration cosegregated with ankle swelling. Consequently, they have been designated $B b a a 2 a$ and $B b a a 2 b$, respectively. Bbaa2a sequence analysis revealed a high degree of conservation between B6 and $\mathrm{C} 3 \mathrm{H}$ mice, exhibiting very low SNP density (21). This interval contains 24 genes (Supplemental Figure 2), none of which are differentially expressed at the transcriptional level between $\mathrm{B} 6$ and $\mathrm{C} 3 \mathrm{H}$ mice following infection, as measured by microarray analysis (20). The Sanger SNP resequencing database (22) indicates that the interval harbors only 1 high-confidence coding nonsynonymous $\mathrm{G} \rightarrow \mathrm{A}$ polymorphism differing between $\mathrm{B} 6$ and $\mathrm{C} 3 \mathrm{H}$ strains, which causes a T87I amino acid change in the ubiquitously expressed lysosomal enzyme Gusb (Figure 1B). 

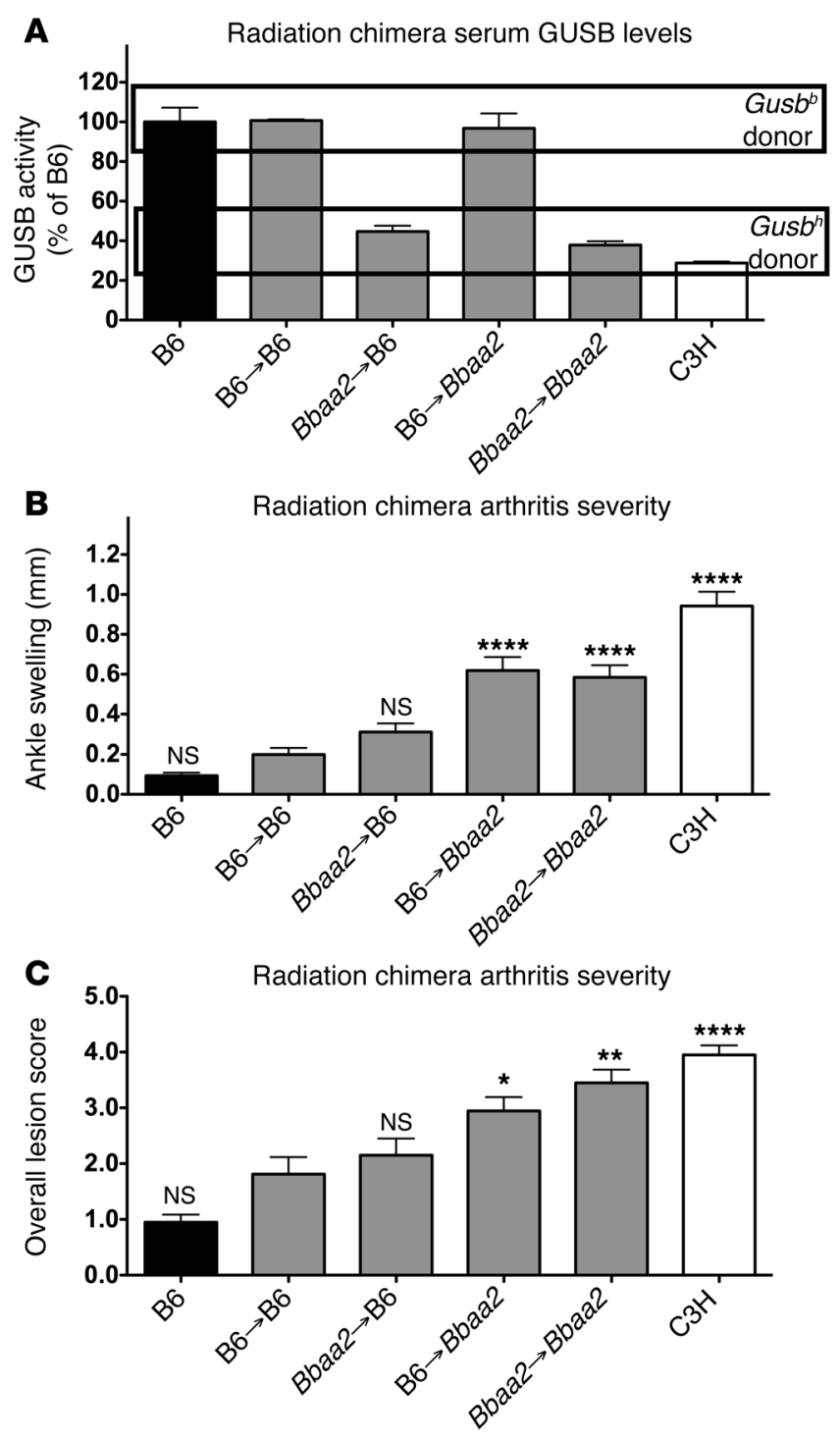

$\mathrm{C} 3 \mathrm{H}$ mice carry a natural variant of Gusb that is functionally bypomorphic. The $\mathrm{C} 3 \mathrm{H}$ strain is known to carry a functionally hypomorphic $\mathrm{Gusb}^{h}$ allele, which confers a $70 \%-90 \%$ reduction in enzymatic activity in the serum and various tissues $(23,24)$. We verified that our B6.C3H-Bbaa2 congenic mice exhibited hypomorphic GUSB enzymatic activity in serum and in cell extracts and supernatants obtained from strain-specific bone marrowderived macrophages (Figure 1C). We observed no significant differences in Gusb mRNA levels between strains or following B. burgdorferi infection, indicating that this hypomorphism manifests posttranscriptionally (Supplemental Figure 3). The Sanger SNP database indicates that only 3 of the 18 included strains, $\mathrm{C} 3 \mathrm{H} / \mathrm{HeJ}, \mathrm{AKR} / \mathrm{J}$, and CBA/J, share this Gusb coding variant. Both $\mathrm{C} 3 \mathrm{H}$ and $\mathrm{AKR} / \mathrm{J}$ have previously been shown to develop severe Lyme arthritis $(13,25)$. Intriguingly, the lower density CDG-MDA1 database shows that unlike CBA/J, a closely related CBA/Ca strain carries the common $\mathrm{B} 6$ reference nucleotide, which we verified by PCR SNP genotyping (Supplemental Figure 4 and ref. 26). These CBA substrains arose from a partially inbred line and have been genetically isolated but never outcrossed (27), suggesting

\section{Figure 3}

GUSB hypomorphism influences arthritis severity through a cell-intrinsic mechanism. Radiation chimeras were generated between B6 and $\mathrm{B} 6 . \mathrm{C} 3 \mathrm{H}-\mathrm{Bbaa} 2$ in all pairwise combinations. We achieved high level $(>90 \%)$ engraftment of B cells and myeloid lineages (Supplemental Figure 6). (A) Chimera serum GUSB activity levels were determined by the donor cell source. (B and $\mathbf{C}$ ) The $\mathrm{C} 3 \mathrm{H}$ Bbaa2 locus contributed to more severe Lyme arthritis, primarily through the activity of radiation resistant joint resident cells. Notably, the B6 $\rightarrow$ Bbaa2 group developed severe Lyme arthritis despite high serum GUSB levels, and the Bbaa2 $\rightarrow$ B 6 group was resistant despite low serum GUSB levels $(n=16$ to 20 rear ankle joints, 8 to 10 mice per group; overall $P<0.0001$ ). Significance of ankle swelling assessed by 1-way ANOVA followed by Dunnet's multiple comparison test versus the $\mathrm{B} 6 \rightarrow \mathrm{B} 6$ transplant control. Significance of overall lesion scores assessed by Mann-Whitney test versus the $\mathrm{B} 6 \rightarrow \mathrm{B} 6$ transplant control, with Bonferroni correction. ${ }^{\star} P<0.05 ;{ }^{* \star} P<0.01 ;{ }^{* \star \star} P<0.0001$.

the Gusb allelic difference is likely to be the result of a limited amount of residual heterozygosity that existed prior to separation. Consistent with this genetic difference, analysis of serum GUSB enzymatic activity levels confirmed that, although CBA/Ca mice had levels similar to those of B6, CBA/J mice were GUSB hypomorphs like $\mathrm{C} 3 \mathrm{H}$ mice (Figure 1D). Following B. burgdorferi infection, $\mathrm{CBA} / \mathrm{J}$ mice developed severe arthritis, while CBA/Ca were resistant (Figure 1E). Importantly, the middensity CDG-MDA1 database identifies only 118 coding nonsynonymous SNPs in the entire genome distinguishing between CBA/Ca and CBA/J mice, and only this Gusb polymorphism was positioned within any of the previously identified Bbaa QTL $(17,19,28)$, including the $B b a a 2 b$ region referenced in Figure $1 \mathrm{~A}$.

Loss of GUSB function exacerbates Lyme arthritis severity in a genetically recessive manner. The availability of a spontaneous Gusb mutant mouse line on the resistant $\mathrm{B} 6$ genetic background, B6.C3HGusb<mps-2J>/BrkJ (Gusb $\left.b^{\text {Null }}\right)$, allowed us to determine the impact of GUSB loss of function in a second, independent mouse line. This Gus $b^{\text {Null }}$ strain is also a congenic line (Methods), and Gusb $b^{\text {Null }}$ homozygotes are used as a mouse model of mucopolysaccharidosis type VII (MPSVII). Importantly, we determined that Gusb $b^{\text {Null }}$ mice exhibit no defect in host defense (Figure 2A) despite expressing only $1 \%$ of normal GUSB levels in homozygotes (Figure 2B). Infected homozygous Gus $b^{\text {Null }}$ mice developed maximally severe Lyme arthritis, while heterozygous littermates carrying 1 functional $G u s b^{b}$ allele were protected (Figure $2 \mathrm{C}$ ). We corroborated the finding that heterozygous animals were protected with both our full-length $\mathrm{B} 6 . \mathrm{C} 3 \mathrm{H}-\mathrm{Bbaa} 2$ and our $\mathrm{B} 6 . \mathrm{C} 3 \mathrm{H}-\mathrm{Gus} b^{b}$ congenic mouse lines (Figure 2, D and E). Thus, neither the severe Gus $b^{\text {Null }}$ allele nor the hypomorphic $G u s b^{b}$ allele act in a dominant negative fashion to interfere with the protective activity of functional $G u s b^{b}$ alleles present in these heterozygous animals.

GUSB hypomorphism acts through a cell-intrinsic mechanism. GUSB functions as a lysosomal hydrolase that requires the low $\mathrm{pH}$ of the lysosome for full enzymatic activity, but is also present in serum. To clarify which pool of GUSB is responsible for its effect on arthritis, radiation chimeras were generated in all pairwise combinations between $\mathrm{B} 6$ and B6.C $3 \mathrm{H}-\mathrm{Bbaa2}$ congenic mice (29). Although the donor cell source, not the recipient genotype, was identified as responsible for serum GUSB levels in chimeric mice (Figure 3A), Lyme arthritis severity was exacerbated in both the $\mathrm{B} 6 \rightarrow \mathrm{B} 6 . \mathrm{C} 3 \mathrm{H}-\mathrm{Bbaa} 2$ and the $\mathrm{B} 6 . \mathrm{C} 3 \mathrm{H}-\mathrm{Bbaa2} \rightarrow \mathrm{B} 6 . \mathrm{C} 3 \mathrm{H}-\mathrm{Bbaa} 2$ groups relative to the $\mathrm{B} 6 \rightarrow \mathrm{B} 6$ control group (Figure $3, \mathrm{~B}$ and $\mathrm{C}$ ). 

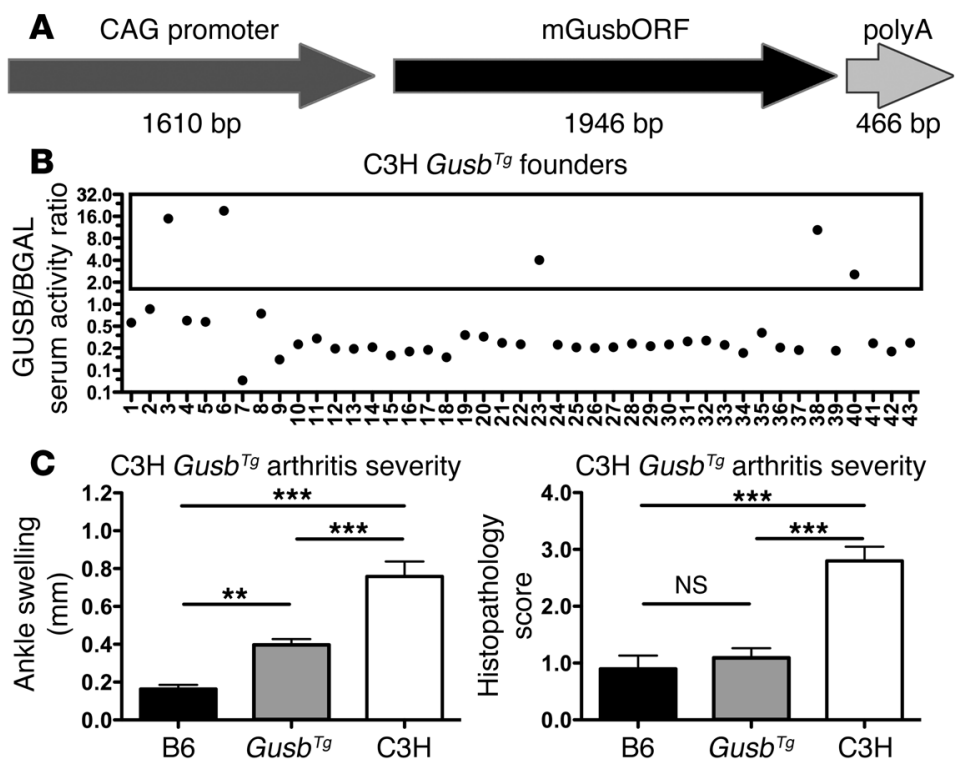

Figure 4

Correction of GUSB hypomorphism in $\mathrm{C} 3 \mathrm{H}$ mice is protective. (A) Transgenic overexpression of mouse Gusb by a pCAGGS-based mammalian expression construct (58). (B) Five founders exhibited elevated GUSB serum activity relative to a $\beta$-galactosidase internal control. (C) C3H Gusb ${ }^{T g}$ mice developed markedly less severe Lyme arthritis than WT C3H controls $(n=10$ for $\mathrm{B} 6$ and $\mathrm{C} 3 \mathrm{H}$ control groups, $n=22$ total Gusb ${ }^{T g}$ progeny from 4 different founders, no. 38 was infertile; overall $P<0.001$ ). Significance assessed by 1-way ANOVA and Bonferroni's post test (ankle swelling) or nonparametric Kruskal-Wallis test and Dunn's multiple comparison test (histopathology). ${ }^{\star \star} P<0.01 ;{ }^{* \star} P<0.001$.

Notably, the disease severity of the $\mathrm{B} 6 \rightarrow \mathrm{B} 6$.C3H-Bbaa2 group was increased despite high GUSB activity levels in the serum. Conversely, B6.C3H-Bbaa2 $\rightarrow$ B6 chimeric mice did not develop significantly more severe disease than the $\mathrm{B} 6 \rightarrow \mathrm{B} 6$ control group, despite low serum GUSB activity. These results indicate that GUSB hypomorphism primarily modulates disease severity within jointresident, radiation-resistant cells and that serum GUSB levels are not determinative. This suggests that GUSB hypomorphism acts through a localized, cell-intrinsic mechanism to initiate the development of inflammatory arthritis.

Transgenic overexpression of $\mathrm{Gusb}^{b}$ in $\mathrm{C} 3 \mathrm{H}$ mice reduces Lyme arthritis severity. Because $G u s b^{b}$ does not appear to interfere with the function of $G u s b^{b}$ in a dominant negative fashion in our various heterozygous experiments and because our radiation chimera experiments implicate joint resident cell types in arthritis development, transgenic overexpression to correct GUSB levels in a hypomorphic strain was considered a reasonable approach. To determine the magnitude of the Gusb effect, a transgene driving ubiquitous mouse Gusb $b^{b}$ expression (Figure 4A) was used to produce $\mathrm{C} 3 \mathrm{H} / \mathrm{HeN}-\mathrm{CAG}-G u s b^{b}$ transgenic mice $\left(G u s b^{T g}\right)$. Five founders were identified that met or exceeded the serum GUSB enzymatic activity levels of B6 mice (Figure 4B). These Gusb ${ }^{T g}$ founders were bred to $\mathrm{C} 3 \mathrm{H} / \mathrm{HeN}$ mice, and progeny with elevated serum GUSB activity levels were selected for infection (Supplemental Figure 5). Although serum GUSB activity levels were not expected to directly influence disease severity, transgenic progeny were screened for serum GUSB activity as a facile surrogate metric of the approximate expression level achieved ubiquitously in all tissues. Following infection with B. burgdorferi, we found that Gusb ${ }^{T g}$ progeny exhibited a profound and highly significant $(P<0.001)$ reduction in disease severity (Figure $4 \mathrm{C}$ ) relative to $\mathrm{WT}$ $\mathrm{C} 3 \mathrm{H}$ control mice. This argues that among the many Bbaa loci previously identified to regulate Lyme arthritis severity in $\mathrm{C} 3 \mathrm{H}$ mice, Gusb is a key regulator.

Evidence of a conserved role for Gusb in a model of rheumatoid arthritis. Because the B6.C3H-Gusb $b^{b}$ congenic line provides the greatest genetic stringency to interrogate the specific impact of GUSB hypomorphism on a resistant genetic background, we used it to determine whether alterations in Gusb modulate disease severity in a way that is unique to Lyme arthritis or whether it plays a more generalized role. To test this, we used the $\mathrm{K} / \mathrm{BxN}$ serum transfer model of rheumatoid arthritis as a second experimental approach to inducing disease $(30,31)$. This model isolates the downstream effector phase of disease pathogenesis from the initiation phase through adoptive transfer of arthritogenic autoantibodies to induce a joint-specific inflammatory arthritis. Injection of submaximal doses of $\mathrm{K} / \mathrm{BxN}$ serum was useful in determining the unique contribution of $G u s b^{b}$ to arthritis severity in this model. Following intraperitoneal injections of $100 \mu \mathrm{K} / \mathrm{BxN}$ serum on days 0 and 2, we found that our B6.C3H-Gusb $b^{b}$ congenic mice began to exhibit more severe ankle swelling than B6 control animals beginning on day 4, which was further exacerbated on day 7 (Figure 5A). Histopathology scores for joints at day 7 also corroborated the significance $(P<0.05)$ of this effect (Figure 5B).

GUSB deficiency is associated with excessive accumulation of glycosaminoglycans during arthritis development. GUSB is a lysosomal hydrolase that catalyzes an essential step in the homeostatic degradation of glycosaminoglycans (GAGs). Severe autosomal recessive GUSB deficiency causes a lysosomal storage disease known as MPSVII, one characteristic of which is spontaneous accumulation of partially degraded GAGs within lysosomes (32). $\mathrm{C} 3 \mathrm{H}$ mice begin to develop mild lysosomal accumulation of GAGs by 12 months of age, but younger 9- to 11-week-old mice appear to be unaffected (33). GAGs and partially degraded fragments have previously been implicated as direct mediators of inflammation through activation of TLRs (34). Rodent models of lysosomal storage disease have been shown to exhibit less severe symptoms following the genetic removal of TLR4 or the pharmaceutical blockade of TNF- $\alpha$ signaling, consistent with an inflammatory component to disease pathogenesis $(35,36)$. To determine whether GAG accumulation occurs during arthritis development in our GUSB-deficient strains, we performed Alcian blue staining to detect the presence of acidic polysaccharides, including GAGs, in joint histopathology sections at 4 weeks after infection. The inflamed tissues from Gusb $b^{\text {Null }}$ and $G u s b^{b}$ strains consistently stained intensely positive for the presence of GAGs. Alcian bluepositive material was identified in the periarticular soft tissue, particularly the tendon sheath, of the joints of Gusb $b^{\text {Null }}$ and Gusb $b^{b}$ strains (Figure 6, B, D, F, and H). GAG accumulation was associated with severe tendonitis manifested by acute inflammation composed of dense neutrophilic infiltrates, tendon hyperproliferation, and synovial hypertrophy. In contrast, no significant accumulation of Alcian blue-positive material or inflammation was detected in joints from $\mathrm{C} 3 \mathrm{H} \mathrm{Gus} b^{T g}$ and other GUSB-sufficient strains (Figure 6, A, C, E, and G). Similarly, joints from day 7 K/BxNtreated B6 control animals lacked GAG accumulation despite 

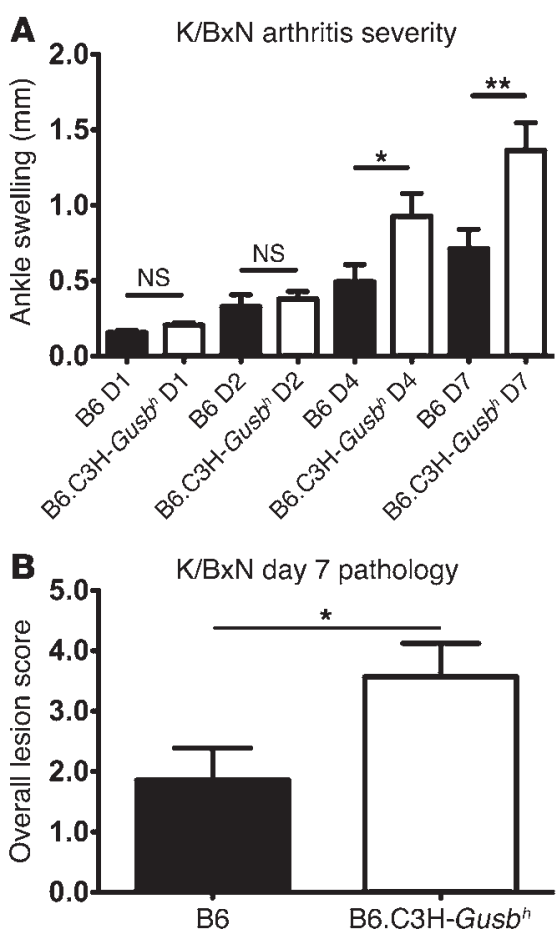

moderate swelling (Figure 6I) in contrast to the severely swollen joints from B6.C3H-Gusb $b^{h}$ congenic mice, which exhibited severe arthritis with extensive accumulation of GAGs throughout the periarticular tissue, including the posterior leg and footpad (Figure 6J). To quantify the approximate magnitude of this effect for each group, all joint sections stained for Alcian blue were scored for GAG accumulation (Figure 6K).

\section{Discussion}

We have uncovered a key role for a naturally occurring hypomorphic $\mathrm{C} 3 \mathrm{H} \mathrm{Gusb}^{b}$ allele in Lyme arthritis severity using a scientifically rigorous QTL mapping approach. All tested inbred mouse strains that carry $G u s b^{b}$ are genetically susceptible to severe Lyme arthritis, and introgression of either $G u s b^{b}$ or the more severe Gus $b^{\text {Null }}$ onto a resistant B6 genetic background confers susceptibility. Importantly, Gus $b^{\text {Null }}$ homozygous animals develop a maximal Lyme arthritis response, equivalent to that of $\mathrm{C} 3 \mathrm{H}$-positive control animals, while strains with the milder hypomorphism conferred by $G u s b^{b}$ develop significant $(P<0.01)$ arthritis of intermediate severity. Additionally, correction of the Gus $b^{b}$ deficiency through transgenic overexpression of $G u s b^{b}$ confers significant $(P<0.001)$ protection to genetically susceptible $\mathrm{C} 3 \mathrm{H}$ mice, conclusively and specifically demonstrating a key role for Gusb.

It is well established that mutations causing frank deficiencies in GUSB result in spontaneous and overt lysosomal storage disease, although mild deficiencies may go unrecognized until late in life and are often misdiagnosed as an inflammatory joint disease (37). Human Gusb is known to be polymorphic, with over 750 SNPs recorded in the dbSNP database. Forty-nine mutations causing overt disease have been identified in MPSVII patient populations (32), while the prevalence and impact, if any, of other variants remain undefined. Human GUSB enzymatic activity levels in the general population have been shown to exhibit a wide distribution and vary in tissue and serum samples by up to 30 -fold $(38,39)$, dif-

\section{Figure 5}

A conserved role for Gusb $b^{h}$ in rheumatoid arthritis. (A) $100 \mu \mathrm{l} \mathrm{K/BxN}$ serum was administered to $\mathrm{B} 6$ and $\mathrm{B} 6 . \mathrm{C} 3 \mathrm{H}-\mathrm{Gusb}^{h}$ congenic mice by intraperitoneal injection on days 0 and 2. Ankle swelling of both rear ankle joints was monitored on days 1, 2, 4, and 7. Congenic mice developed significantly more robust ankle swelling starting on day 4 that was further exacerbated on day 7 , and this finding was corroborated by blinded joint histopathology measurements (B) $(n=14$ rear ankle joints for each group). Pairwise significance of ankle swelling calculated by Student's $t$ test. Significance of overall lesion score assessed by MannWhitney test. ${ }^{*} P<0.05 ;{ }^{* \star} P<0.01$.

ferences larger than those observed between high-expressing (B6, $\mathrm{CBA} / \mathrm{Ca})$ and low-expressing $(\mathrm{C} 3 \mathrm{H}, \mathrm{CBA} / \mathrm{J})$ inbred mouse strains used in this study (Figure 1D and ref. 33). GUSB may be uniquely sensitive to mild deficiencies in enzymatic activity, since it has been suggested as the rate-limiting enzyme in the dermatan sulfate degradative pathway (40). Severe deficiencies in individual lysosomal enzymes causing overt disease are rare, with a combined incidence estimated at up to 1 in 5,000 births (41), far below the practical limit of detection of genome wide association studies (GWAS) (minor allele frequency $>0.05$ ) (42). Although human genetic susceptibility to Lyme arthritis has not been investigated by GWAS, it is noteworthy that thus far only a fraction of the genetic variance underlying rheumatoid arthritis has been identified by GWAS (43), accentuating the added value of our QTL mapping approach.

Our studies have identified a naturally occurring, mild subclinical GUSB deficiency that transforms the normally protective local response to B. burgdorferi into a fulminating inflammatory arthritis. Recent literature has brought attention to the persistence of bacterial antigen in host tissues, even following antibiotic regimens that effectively cleared cultivable bacteria (44). Importantly, the increased disease severity we have observed occurs in the absence of significant alterations in host defense or B. burgdorferi load in tissues (Figure 2A). This disease exacerbation is also retained in the distinct and well-characterized $\mathrm{K} / \mathrm{BxN}$ serum transfer model of rheumatoid arthritis, where dosage of the inflammatory stimulus can be tightly controlled. This suggests that inflammatory initiators such as B. burgdorferi antigen or autoantibodies trigger severe disease through a 2-hit phenomenon, where coincident breakdown of host tolerance mechanisms designed to limit the pathological consequences of infection and the ensuing inflammatory response instead exacerbate disease symptoms. The ability of $G u s b^{b}$ to exacerbate arthritis in response to very different experimental stimuli suggests this phenomenon may also be generalizable to other inflammatory triggers.

Our observation that radiation-resistant, joint-resident cells are a primary determinant of the magnitude of the Lyme arthritis response offers important insight into the mechanisms underlying joint pathogenesis in this model. This finding indicates that resident cells have important roles both in recruiting inflammatory immune cells to help clear infection and in mitigating damage through tolerance mechanisms. Our complementary finding that the severe joint pathology observed in infected B6.C3H-Bbaa2 mice is not effectively corrected by high-serum GUSB levels bears striking resemblance to reports on the limited efficacy of enzyme replacement therapy to alleviate musculoskeletal symptoms in adult animal models of MPSVII $(45,46)$, although early intervention in neonates has shown promise $(47,48)$. Similarly, the joint pathologies in patients with a variety of mucopolysaccharidoses are difficult to treat and respond 

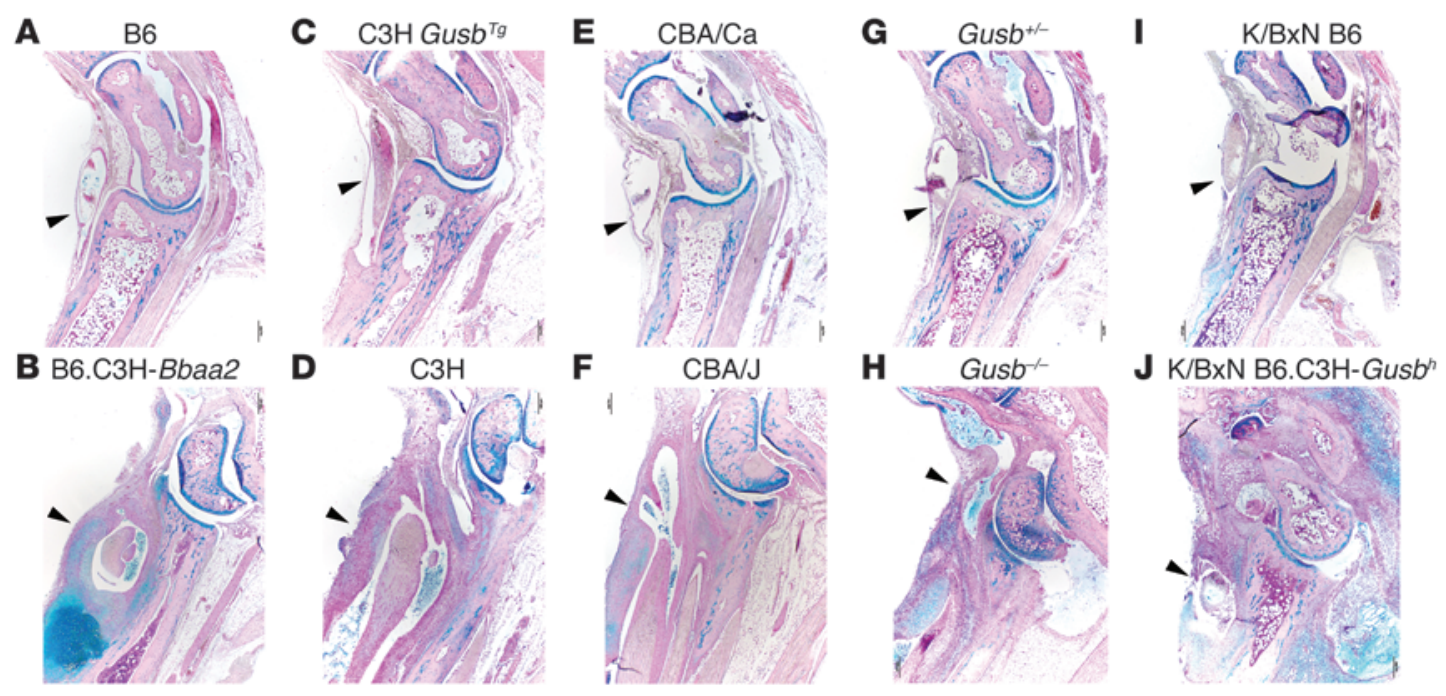

$\mathbf{K}$

B. burgdorferi-infected joints
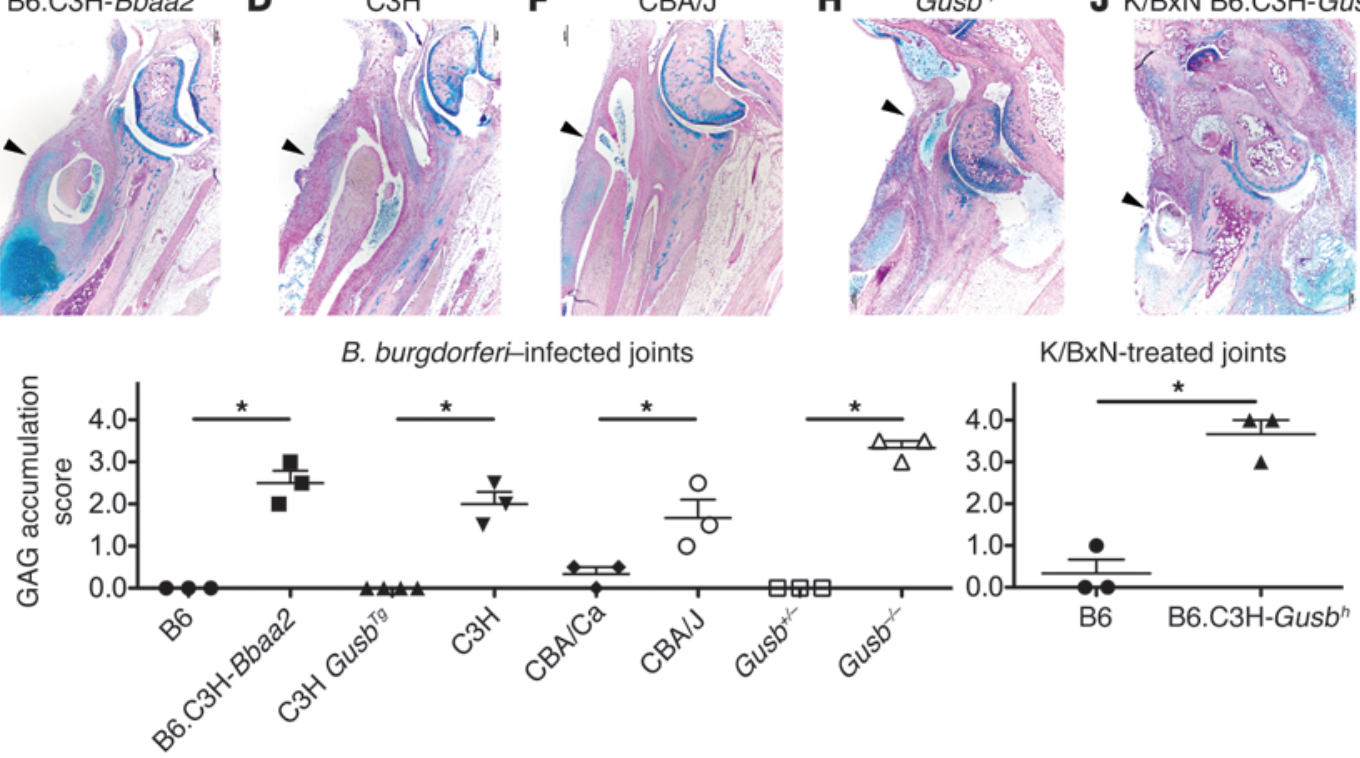

\section{Figure 6}

GUSB enzymatic hypomorphism is associated with exaggerated accumulation of GAGs in the inflamed joint. Representative images of Alcian blue-stained rear ankle joint sections from B. burgdorferi-infected GUSB-sufficient (upper panels: A, C, E, and G) or GUSB-deficient (lower panels: B, D, F, and $\mathbf{H}$ ) strains, or day $7 \mathrm{~K} / \mathrm{BxN}$-treated $\mathrm{B} 6(\mathbf{I})$ and $\mathrm{B} 6 . \mathrm{C} 3 \mathrm{H}-\mathrm{Gush} b^{h}(\mathbf{J})$ congenic mice. Arrowheads indicate position of the cranial tibial tendon sheath. Original magnification, $\times 4$. Scale bars: $500 \mu \mathrm{m}(\mathrm{K}) \mathrm{GAG}$ accumulation in the soft tissue and joint/synovial space was scored on a scale of $0-4$ ( $n=3$ to 4 joints per group). Pairwise significance assessed by 1-tailed Mann-Whitney test. ${ }^{*} P<0.05$.

much more slowly to high-dose enzyme replacement therapy than other symptoms, such as hepatosplenomegaly or sleep apnea (49). Taken together, these findings highlight the importance of the primary response to bacterial stimulation that is mounted by resident cells in these refractory joint tissues.

The evident link between GUSB hypomorphism and excessive deposition of GAGs with potential proinflammatory activity provides a plausible mechanism bridging disease to the critical catalytic role GUSB plays in homeostatic GAG degradation. Although our data show no significant change in bacterial load due to GUSB deficiency, GAG-mediated cell adhesion by B. burgdorferi does play a noteworthy role in mammalian infection and tissue localization (50). The GUSB substrate dermatan sulfate has been linked to excessive TNF- $\alpha$ release by chondrocytes (40), and MPSVI symptoms are alleviated by blocking TNF- $\alpha$ (36), a highly successful target for rheumatoid arthritis (51). However, this does not preclude the involvement of other downstream effectors. The release and accumulation of lysosomal exoglycosidases in the serum has been observed in multiple forms of chronic inflammatory arthritis, with localized release into synovial fluid reported to be especially exaggerated in chronic Lyme arthritis patients $(52,53)$. Although lysosomal exoglycosidases such as GUSB are catalytically inactive at neutral $\mathrm{pH}$, coincident release of other proinflammatory lyso- somal components may provide an alternate mechanism to trigger or amplify a local inflammatory cascade (54). We suggest that the identification of Gusb as a key regulator of murine Lyme and rheumatoid arthritis severity provides a sound scientific basis for future investigations into serum GUSB or GAG levels as potential biomarkers of human susceptibility to developing chronic or severe inflammatory arthritis.

Gusb is 1 member of a large group of over 40 coregulated lysosomal enzymes in the coordinated lysosomal expression and regulation (CLEAR) network that are responsible for the stepwise degradation of several distinct biological substrates, including GAGs, lipids, sugars, chitin, and glycogen (55). As with Gusb, severe deficiencies in virtually all of these enzymes induce spontaneous lysosomal storage disease. Many such lysosomal storage diseases exhibit progressive joint disease. Recent work has demonstrated that overexpression of the master regulatory transcription factor of the CLEAR network, TFEB, leads to successful clearance of glycogen from lysosomes in both in vitro and mouse models of Pompe disease (56). Based on the close regulatory and functional interrelationship between Gusb and other lysosomal enzymes, we propose that the increased arthritis severity observed in this study may also be generalizable to mild deficiencies in other members of the CLEAR network. 


\section{Methods}

\section{Generation of interval-specific congenic lines}

Interval-specific congenic lines (ISCL) were generated as described (19). Standard nomenclature for the mouse lines is used herein, as follows: the background strain (e.g., C57BL/6NCr, abbreviated B6 in the ISCL designations) is listed first, followed by the donor strain (e.g., $\mathrm{C} 3 \mathrm{H})$ and the introgressed interval on mouse chromosome 5 (in Mbp, according to the NCBI37/mm9 Mouse Genome Assembly) from C3H/HeNCr into the C57BL/6NCr parental strain (National Cancer Institute). B6.C3H-120.3-141.2 (Full Length, B6.C $3 \mathrm{H}-B b a a 2)$, B6.C $3 \mathrm{H}-120.3-121.6$, B6.C $3 \mathrm{H}-120.3-125.6$, B6.C3H-120.3-126.6, В6.C3H-120.3-128.2, В6.C3H-125.3-128.2, B6.C3H-120.3-131.0, B6.C3H-125.3-131.8, B6.C3H-129.0-130.5 (B6.C3H$\left.\mathrm{Gusb}^{b}\right)$, В6.С $3 \mathrm{H}-129.0-141.2$, В6.С $3 \mathrm{H}-131.8-133.5$, В6.С $3 \mathrm{H}-131.8-141.2$, B6.C3H-134.7-141.2, and B6.C3H-136.4-141.2 ISCL were generated by marker-assisted selection using high-resolution melting analysis SNP genotyping primers as described (21). Homozygous progeny derived from mating heterozygous male and female ISCL mice that were free of background donor strain contamination were used to fix the lines.

\section{Gusb $b^{\text {Null }}$ mice}

Gus $b^{\text {Null }}$ mice were obtained from Jackson Laboratory, as a mouse model of MPSVII. Gusb $b^{\text {Null }}$ mice were derived from heterozygous breeder pairs, and homozygous offspring were identified at markedly sub-Mendelian ratios (data not shown) by SNP genotyping and reduced body size. As per Jackson Laboratory documentation, this spontaneous mutant mouse line originally arose in the $\mathrm{C} 3 \mathrm{H} / \mathrm{HeOuJ}$ stock production colony and was extensively backcrossed to C57BL/6J. As a result, these mice are congenic for the Gusb locus and carry the $G u s b^{b}$ allele. Upon receipt, we determined that the flanking interval carried by this strain was approximately $20 \mathrm{Mb}$ in size (data not shown) and that this line therefore provides less genetic specificity than the much narrower 1.5-Mb B6.C3H-Gusb ${ }^{b}$ congenic line. The more severe GUSB deficiency observed in this strain has been attributed to a $5.4 \mathrm{~kb}$ intracisternal A-particle (IAP) transposon insertion near the $3^{\prime}$ end of intron 8 (57).

\section{Generation of $\mathrm{C} 3 \mathrm{H} / \mathrm{HeN}-\mathrm{CAG}-\mathrm{G} u \boldsymbol{s}^{b}$ transgenic mice $^{-}$}

All PCR steps were performed for 25 cycles with high-fidelity Phusion Taq DNA Polymerase (Thermo Scientific) in $1 \times$ HF buffer, following the manufacturer's recommendations, on a LightCycler 480 Platform (Roche Applied Science).

All agarose gel electrophoresis steps were performed with $1 \%$ agarose gels in $1 \times$ TBE buffer ( $89 \mathrm{mM}$ Tris base, $89 \mathrm{mM}$ boric acid, $2 \mathrm{mM}$ EDTA), unless otherwise specified.

All band visualization was performed by ethidium bromide staining on a Gel Doc XR+ platform (Bio-Rad Laboratories).

All agarose gel purification steps were performed with a GeneJet Gel Extraction kit (Fermentas), according to the manufacturer's recommendations, unless otherwise specified.

Gusb $b^{b}$ insert preparation. The open reading frame of the cDNA coding sequence from MGC cDNA clone 78180 (IMAGE:5325429) was PCR amplified with an annealing temperature of $71^{\circ} \mathrm{C}$. The following sequence-specific primers containing $5^{\prime}$ EcoRI cloning sites produced approximately 2000-bp amplicon: mGusbORF-forward, CCGGTAGAATTCATGTCCCTAAAATGGAGTGCGTGT, mGusbORF-reverse, CCGGTTGAATTCTTAGAACGTGAACGGTCTGCTTCC. The PCR product was incubated with EcoRI restriction enzyme for 1 hour at $37^{\circ} \mathrm{C}$, then separated by agarose gel electrophoresis. A band of the predicted size was visualized, excised, and gel purified.

pCAGGS preparation. A mammalian overexpression construct previously shown to drive high-level expression of human GUSB in mice (58) was pro- vided by Mark Sands (Washington University, St. Louis, Missouri, USA). The human Gusb cDNA insert was removed by cleavage with EcoRI, releasing a $2.2-\mathrm{kb}$ fragment of the predicted size, which was then separated from the backbone by agarose gel electrophoresis. The backbone was excised and gel purified. The purified Gusb $b^{b}$ ORF fragment was cloned into pCAGGS EcoRI and validated by fully sequencing across the insert.

Purification of the CAG-Gusb fragment. The transgenic fragment was removed from the backbone by cleavage with EarI and SpeI restriction enzymes and separated by electrophoresis in $1 \times$ TAE buffer on a $1 \%$ agarose gel. The approximately 4174-bp fragment was excised, removed from the gel slice by electroelution in $3 \mathrm{ml}$ of $1 \times$ TAE buffer run at 100 volts for 1 hour. The fragment was then purified using an ELUTIP column (Whatman) according to the manufacturer's recommendations and resuspended in low EDTA-TE injection buffer (10 mM Tris/0.1 mM EDTA pH 7.5). $2 \mu \mathrm{g}$ of the purified fragment was provided to the University of Utah Transgenic and Gene Targeting Mouse Core Facility for microinjection into embryos derived from $\mathrm{C} 3 \mathrm{H} / \mathrm{HeN}$ mice (National Cancer Institute).

A total of 43 mice were screened for presence of the $G u s b^{b}$ transgene by PCR genotyping of genomic DNA using intron-spanning primers: forward, 5'-CCCAGCCAATAAAGTCCCGAAG-3', reverse, 5'-GGCCCAGTCTTGGACATGC-3'. They were also screened for serum GUSB activity levels, normalized to $\beta$-galactosidase activity as an internal control (Figure 4B).

\section{GUSB enzymatic activity assay}

4-Methylumbelliferyl $\beta$-D-glucuronide (MUG) (Marker Gene) was used as a fluorogenic substrate to measure GUSB enzymatic activity. $10 \mu \mathrm{l}$ of sample (serum, cell extract, or supernatant) was incubated with $1 \mathrm{mM}$ MUG in a total volume of $50 \mu \mathrm{l}$ assay buffer $(200 \mathrm{mM}$ sodium acetate; $\mathrm{pH} 4.5 ; 10$ mM EDTA; $0.01 \%$ BSA; $0.1 \%$ Triton X-100) for 1 hour at $37^{\circ} \mathrm{C}$ in a 96-well plate (\#3370; Costar). $150 \mu$ l of stop buffer (200 mM sodium carbonate) was then added, and samples were analyzed on a Biotek Synergy HT microplate reader. Fluorescence was measured with an excitation wavelength of $360 \mathrm{~nm}$ and an emission wavelength of $460 \mathrm{~nm}$. Units were calculated by comparison against a standard curve prepared using purified bovine liver glucuronidase (type B-1 \#G0251; Sigma-Aldrich). Measurements of $\beta$-galactosidase activity were performed in a similar manner using 4-methylumbelliferyl $\beta$-D-galactopyranoside (Marker Gene) as a substrate.

\section{Culture and analysis of bone marrow-derived macrophages}

BMM $\phi$ were prepared as described (19) by culture in RPMI 1640 medium (Invitrogen) supplemented with 30\% L929 conditioned medium and 20\% horse serum (HyClone). Harvested macrophages were replated into 12-well plates at a density of $6 \times 10^{5} / \mathrm{ml}$ in medium lacking serum and containing $1 \%$ Nutridoma. Supernatants were harvested 24 hours later, cells were washed once with $1 \times$ PBS, and cell extracts were then harvested by incubation in extraction buffer (50 mM NaPO4, pH 7.0; 10 mM BME; $10 \mathrm{mM}$ EDTA; $0.1 \%$ sarcosyl; $0.1 \%$ Triton X-100).

\section{Culture of B. burgdorferi and infection of mice}

Mice between 6 and 7 weeks of age were infected by intradermal injection with $2 \times 10^{3}$ bacteria of the B. burgdorferi $\mathrm{N} 40$ isolate (provided by Stephen Barthold, UCD, Davis, California, USA). B. burgdorferi cells were cultured in BarbourStoenner-Kelly II medium containing 6\% rabbit serum (Sigma-Aldrich).

\section{Arthritis analysis}

Rear ankle joints were measured at the time of infection and at 4 weeks after infection by using a metric caliper, as described (19). Measurements of the thickest anteroposterior portion of the ankle with the joint extended were taken and are reported as the change in ankle swell- 
ing over time. A histological assessment of arthritis severity was performed with the most swollen ankle joint. Tissues were fixed in 10\% neutral buffered formalin, decalcified, embedded in paraffin, and cut into $3-\mu \mathrm{m}$-thick sections; sections were mounted onto glass slides and stained with $\mathrm{H} \& \mathrm{E}$ or with Alcian blue. The H\&E-stained joint sections were evaluated blindly and scored for the severity of injury according to a subjective scale ranging from 0 to 5 . A score of 0 indicated no lesions, and scores of 1, 2, 3, 4, and 5 indicated minimal, mild, moderate, marked, and severe lesions, respectively. The overall lesion score represented a combined assessment of neutrophil infiltration, mononuclear cell infiltration, tendon sheath thickness, and reactive-reparative responses. To assess GAG accumulation, joint sections from each group were given a subjective score based on the presence of Alcian blue-positive material in the soft tissue and joint/synovial space, ranging from 0 (none) to 4 (severe).

\section{Generation and analysis of radiation chimeras}

Chimeras were generated in all pairwise combinations between B6 CD45.1 and B6.C3H-Bbaa2 (CD45.2) congenic mice as described (29). Briefly, 4-week-old mice were lethally irradiated with 2 doses of 525 cGy given 3 hours apart using a GE Isovolt Titan (GE Healthcare). 24 hours later, splenocytes were prepared from donor mice. Irradiated mice each received an intravenous injection of $2 \times 10^{7}$ splenocytes in a $200 \mu \mathrm{l}$ volume. Chimerism was evaluated at 3 weeks after transplant by flow cytometric analysis of blood leukocytes (Supplemental Figure 6).

\section{$K / B x N$ serum transfer}

$\mathrm{K} / \mathrm{BxN}$ serum was a gift from Paul Allen (Washington University). Rear ankle joints were measured with a metric caliper prior to treatment, as described above. $100 \mu \mathrm{l}$ of $\mathrm{K} / \mathrm{BxN}$ serum was administered by intraperitoneal injections on days 0 and 2 . Ankle swelling was determined by measurements on days 1, 2, 4, and 7 . After the final day 7 measurement, joint histopathology was assessed, as described above.

\section{Imaging of joint histology sections}

Alcian blue-stained sections were visualized on an Olympus BX41 clinical microscope (Olympus America) using $\times 4$ total magnification. Images were recorded with an Olympus DP72 camera and prepared using Olympus cellSens digital imaging software.

\section{Statistics}

All data represent mean \pm SEM. All statistical calculations were performed using GraphPad Prism 5. $P<0.05$ was considered statistically significant. Continuous variables were analyzed by 1-way ANOVA and Student's $t$ test. Categorical variables were analyzed by Kruskal-Wallis or Mann-Whitney nonparametric tests. All calculations of Student's $t$ tests and Mann-Whitney tests are 2-tailed unless otherwise specified.

\section{Study approval}

All study protocols involving mice were conducted in accordance with the $\mathrm{NIH}$ guidelines for the care and use of animals and approved by the Institutional Animal Care and Use Committee at the University of Utah.

\section{Acknowledgments}

We thank Mark Sands (Washington University) for providing the pCAGG- $\beta$-gluc mammalian expression plasmid that was used to create our transgenic overexpression construct. Paul Allen (Washington University) kindly provided $\mathrm{K} / \mathrm{BxN}$ serum. The project described was supported by award T32AI055434 (to K.C. Bramwell), 6133/Arthritis Foundation (to K.C. Bramwell), AI32223/National Institute of Allergy and Infectious Diseases (NIAID) (to J.J. Weis), AR-43521/National Institute of Arthritis and Musculoskeletal and Skin Diseases (NIAMS) (to C. Teuscher and J.J. Weis), NS061014/ National Institute of Neurological Disorders and Stroke (NINDS) (to C. Teuscher), AI041747/NIAID (to C. Teuscher), NS060901/ NINDS (to C. Teuscher), NS036526/NINDS (to C. Teuscher), and NS069628/NINDS (to C. Teuscher). The DNA/Peptide Core is supported in part by Cancer Center Support grant P30 CA04201. We thank Lynn Sonderegger and Robert Lochhead for helpful discussions. The content is solely the responsibility of the authors and does not necessarily represent the official views of the NIH. This paper is subject to the NIH Public Access Policy.

Received for publication July 26, 2013, and accepted in revised form October 10, 2013.

Address correspondence to: Janis J. Weis, 15 North Medical Drive East \#2100, Salt Lake City, Utah 84112-5650, USA. Phone: 801.581.8386; Fax: 801.585.2417; E-mail: janis.weis@path.utah.edu.
1. Burgdorfer W, Barbour AG, Hayes SF, Benach JL, Grunwaldt E, Davis JP. Lyme disease-a tick-borne spirochetosis? Science. 1982;216(4552):1317-1319.

2. Reported Cases of Lyme Disease by Year, United States, 2003-2012. Lyme Disease Information Web site. http://www.cdc.gov/lyme/stats/chartstables/ casesbyyear.html. Updated September 16, 2013. Accessed October 7, 2013.

3. How many people get Lyme disease? Lyme Disease Information Web site. http://www.cdc.gov/lyme/ faq/index.html\#humanCases. Updated August 19, 2013. Accessed October 7, 2103.

4. Steere AC, Schoen RT, Taylor E. The clinical evolution of Lyme arthritis. Ann Intern Med. 1987; 107(5):725-731.

5. Clinical Manifestations of Confirmed Lyme Disease Cases, United States, 2001-2010. Lyme Disease Information Web site. http://www.cdc.gov/lyme/ stats/chartstables/casesbysymptom.html. Updated April 13, 2012. Accessed October 7, 2013.

6. Wormser GP, et al. Borrelia burgdorferi genotype predicts the capacity for hematogenous dissemination during early Lyme disease. J Infect Dis. 2008; 198(9):1358-1364.

7. Schroder NW, et al. Heterozygous Arg753Gln polymorphism of human TLR-2 impairs immune activation by Borrelia burgdorferi and protects from late stage Lyme disease. J Immunol. 2005; 175(4):2534-2540.

8. Strle K, Shin JJ, Glickstein LJ, Steere AC. Association of a Toll-like receptor 1 polymorphism with heightened Th1 inflammatory responses and antibioticrefractory Lyme arthritis. Arthritis Rheum. 2012; 64(5):1497-1507.

9. Alexopoulou L, et al. Hyporesponsiveness to vaccination with Borrelia burgdorferi OspA in humans and in TLR1- and TLR2-deficient mice. Nat Med. 2002;8(8):878-884.

10. Fernando MM, et al. Defining the role of the MHC in autoimmunity: a review and pooled analysis. PLoS Genet. 2008;4(4):e1000024.

11. Drouin EE, et al. A novel human autoantigen, endothelial cell growth factor, is a target of $\mathrm{T}$ and $\mathrm{B}$ cell responses in patients with Lyme disease. Arthritis Rheum. 2013;65(1):186-196.

12. Steere AC, et al. Antibiotic-refractory Lyme arthritis is associated with HLA-DR molecules that bind a Borrelia burgdorferi peptide. J Exp Med. 2006; 203(4):961-971.

13. Barthold SW, Beck DS, Hansen GM, Terwilliger GA, Moody KD. Lyme borreliosis in selected strains and ages of laboratory mice. J Infect Dis. 1990;
162(1):133-138

14. Radolf JD, Caimano MJ, Stevenson B, Hu LT. Of ticks, mice and men: understanding the dual-host lifestyle of Lyme disease spirochaetes. Nat Rev Microbiol. 2012;10(2):87-99.

15. Norris SJ. Antigenic variation with a twist - the Borrelia story. Mol Microbiol. 2006;60(6):1319-1322.

16. Petkov PM, et al. An efficient SNP system for mouse genome scanning and elucidating strain relationships. Genome Res. 2004;14(9):1806-1811.

17. Weis JJ, et al. Identification of quantitative trait loci governing arthritis severity and humoral responses in the murine model of Lyme disease. J Immunol. 1999;162(2):948-956.

18. Roper RJ, et al. Genetic control of susceptibility to experimental Lyme arthritis is polygenic and exhibits consistent linkage to multiple loci on chromosome 5 in four independent mouse crosses. Genes Immun. 2001;2(7):388-397.

19. Ma Y, et al. Interval-specific congenic lines reveal quantitative trait Loci with penetrant lyme arthritis phenotypes on chromosomes 5, 11, and 12 . Infect Immun. 2009;77(8):3302-3311.

20. Crandall H, et al. Gene expression profiling reveals unique pathways associated with differential severity of lyme arthritis. J Immunol. 2006;177(11):7930-7942. 
21. Bramwell KK, Ma Y, Weis JH, Teuscher C, Weis JJ. High-throughput genotyping of advanced congenic lines by high resolution melting analysis for identification of Bbaa2, a QTL controlling Lyme arthritis. Biotechniques. 2012;52(3):183-190.

22. Keane TM, et al. Mouse genomic variation and its effect on phenotypes and gene regulation. Nature. 2011;477(7364):289-294.

23. Morrow AG, Greenspan EM, Carroll DM. Liverglucuronidase activity of inbred mouse strains. J Natl Cancer Inst. 1949;10(3):657-661.

24. Lusis AJ, Chapman VM, Wangenstein RW, Paigen K. Trans-acting temporal locus within the beta-glucuronidase gene complex. Proc Natl Acad Sci U S A. 1983;80(14):4398-4402.

25. Schaible UE, Kramer MD, Wallich R, Tran T, Simon MM. Experimental Borrelia burgdorferi infection in inbred mouse strains: antibody response and association of $\mathrm{H}-2$ genes with resistance and susceptibility to development of arthritis. Eur J Immunol. 1991;21(10):2397-2405.

26. Ye S, Dhillon S, Ke X, Collins AR, Day IN. An efficient procedure for genotyping single nucleotide polymorphisms. Nucleic Acids Res. 2001;29(17):E88-E88.

27. Whitmore AC, Whitmore SP. Subline divergence within L.C. Strong's C3H and CBA inbred mouse strains. A review. Immunogenetics. 1985;21(5):407-428.

28. Yang H, et al. Subspecific origin and haplotype diversity in the laboratory mouse. Nat Genet. 2011; 43(7):648-655.

29. Sonderegger FL, et al. Localized production of IL-10 suppresses early inflammatory cell infiltration and subsequent development of IFN-gamma-mediated Lyme arthritis. J Immunol. 2012; 188(3):1381-1393.

30. Kouskoff V, Korganow AS, Duchatelle V, Degott C, Benoist C, Mathis D. Organ-specific disease provoked by systemic autoimmunity. Cell. 1996; 87(5):811-822.

31. Korganow AS, et al. From systemic T cell self-reactivity to organ-specific autoimmune disease via immunoglobulins. Immunity. 1999;10(4):451-461.

32. Tomatsu S, Montano AM, Dung VC, Grubb JH, Sly WS. Mutations and polymorphisms in GUSB gene in mucopolysaccharidosis VII (Sly Syndrome). Hum Mutat. 2009;30(4):511-519.

33. Yatsiv S, Erickson RP, Sandman R, Robertson WV. Glycosaminoglycan accumulation with partial deficiency of beta-glucuronidase in the $\mathrm{C} 3 \mathrm{H}$ strain of mice. Biochem Genet. 1978;16(11-12):1079-1084. 34. Taylor KR, et al. Recognition of hyaluronan released in sterile injury involves a unique receptor complex dependent on Toll-like receptor 4, CD44, and MD-2.J Biol Chem. 2007;282(25):18265-18275.

35. Eliyahu E, Wolfson T, Ge Y, Jepsen KJ, Schuchman $\mathrm{EH}$, Simonaro CM. Anti-TNF- $\alpha$ therapy enhances the effects of enzyme replacement therapy in rats with mucopolysaccharidosis type VI. PLoS One. 2011;6(8):e22447.

36. Simonaro CM, Ge Y, Eliyahu E, He X, Jepsen KJ, Schuchman EH. Involvement of the Toll-like receptor 4 pathway and use of TNF- $\alpha$ antagonists for treatment of the mucopolysaccharidoses. Proc Natl Acad Sci U S A. 2010;107(1):222-227.

37. Morishita K, Petty RE. Musculoskeletal manifestations of mucopolysaccharidoses. Rheumatology (Oxford). 2011;50(suppl 5):v19-v25.

38. Sperker B, Murdter TE, Schick M, Eckhardt K, Bosslet K, Kroemer HK. Interindividual variability in expression and activity of human beta-glucuronidase in liver and kidney: consequences for drug metabolism. J Pharmacol Exp Ther. 1997;281(2):914-920.

39. Lombardo A, et al. Plasma lysosomal glycohydrolases in a general population. Clin Chim Acta. 1996; 247(1-2):39-49.

40. Fuller M, Meikle PJ, Hopwood JJ. Glycosaminoglycan degradation fragments in mucopolysaccharidosis I. Glycobiology. 2004;14(5):443-450.

41. Fuller M, Meikle PJ, Hopwood JJ. Epidemiology of lysosomal storage diseases: an overview. In: Mehta A, Beck M, Sunder-Plassmann G, eds. Fabry Disease: Perspectives From 5 Years of FOS. Oxford, United Kingdom: Oxford PharmaGenesis Ltd; 2006:9-20.

42. Risch N, Merikangas K. The future of genetic studies of complex human diseases. Science. 1996; 273(5281):1516-1517.

43. Eyre S, et al. High-density genetic mapping identifies new susceptibility loci for rheumatoid arthritis. Nat Genet. 2012;44(12):1336-1340.

44. Bockenstedt LK, Gonzalez DG, Haberman AM Belperron AA. Spirochete antigens persist near cartilage after murine Lyme borreliosis therapy. J Clin Invest. 2012;122(7):2652-2660.

45. Xing EM, et al. The effect of neonatal gene therapy on skeletal manifestations in mucopolysaccharidosis VII dogs after a decade. Mol Genet Metab. 2013; 109(2):183-193.

46. Birkenmeier EH, et al. Increased life span and correction of metabolic defects in murine mucopolysaccharidosis type VII after syngeneic bone marrow transplantation. Blood. 1991;78(11):3081-3092.

47. Vogler C, Sands MS, Levy B, Galvin N, Birkenmeier
EH, Sly WS. Enzyme replacement with recombinant beta-glucuronidase in murine mucopolysaccharidosis type VII: impact of therapy during the first six weeks of life on subsequent lysosomal storage, growth, and survival. Pediatr Res. 1996; 39(6):1050-1054.

48. Sands MS, et al. Treatment of murine mucopolysaccharidosis type VII by syngeneic bone marrow transplantation in neonates. Lab Invest. 1993; 68(6):676-686.

49. Valayannopoulos V, Wijburg FA. Therapy for the mucopolysaccharidoses. Rheumatology (Oxford). 2011; 50(suppl 5):v49-v59.

50. Coburn J, Fischer JR, Leong JM. Solving a sticky problem: new genetic approaches to host cell adhesion by the Lyme disease spirochete. Mol Microbiol. 2005;57(5):1182-1195.

51. van Vollenhoven RF. Treatment of rheumatoid arthritis: state of the art 2009. Nat Rev Rheumatol. 2009;5(10):531-541.

52. Pancewicz S, et al. Activity of lysosomal exoglycosidases in serum and synovial fluid in patients with chronic Lyme and rheumatoid arthritis. Scand J Infect Dis. 2009;41(8):584-589.

53. Pancewicz S, et al. Activity of lysosomal exoglycosidases in the serum of patients with chronic Lyme arthritis. Int J Med Microbiol. 2006; 296(suppl 40):280-282.

54. Holt OJ, Gallo F, Griffiths GM. Regulating secretory lysosomes. J Biochem. 2006;140(1):7-12.

55. Palmieri $M$, et al. Characterization of the CLEAR network reveals an integrated control of cellular clearance pathways. Hum Mol Genet. 2011; 20(19):3852-3866.

56. Spampanato C, et al. Transcription factor EB (TFEB) is a new therapeutic target for Pompe disease. EMBO Mol Med. 2013;5(5):691-706.

57. Gwynn B, Lueders K, Sands MS, Birkenmeier EH. Intracisternal A-particle element transposition into the murine beta-glucuronidase gene correlates with loss of enzyme activity: a new model for betaglucuronidase deficiency in the $\mathrm{C} 3 \mathrm{H}$ mouse. $\mathrm{Mol}$ Cell Biol. 1998;18(11):6474-6481.

58 . Vogler $\mathrm{C}$, et al. Transgene produces massive overexpression of human $\beta$-glucuronidase in mice, lysosomal storage of enzyme, and strain-dependent tumors. Proc Natl Acad Sci U S A. 2003;100(5):2669-2673.

59. Morrison TB, Ma Y, Weis JH, Weis JJ. Rapid and sensitive quantification of Borrelia burgdorferi-infected mouse tissues by continuous fluorescent monitoring of PCR. J Clin Microbiol. 1999;37(4):987-992. 